\section{A comprehensive medical history}

\section{The Western Medical Tradition: 1800 to 2000 \\ by W. F. Bynum, Anne Hardy, Stephen Jacyna, Christopher Lawrence \& E. M. (Tilli) Tansey \\ Cambridge University Press: 2006.614 pp. $\$ 90, £ 50$ (hbk); $€ 19.99, \$ 29.99$ (pbk). \\ Available as a two-volume set with The Westem Medical Tradition 800 BC to AD 1800. $\$ 70, £ 40$}

\section{Andreas-Holger Maehle}

"The social history of medicine has come of age," stated historian Andrew Wear nearly 15 years ago in the introduction to Medicine in Society (Cambridge University Press, 1992), a collection of historical essays that became popular as a textbook. After reading The Western Medical Tradition: 1800 to 2000, by Bill Bynum and colleagues at the Wellcome Trust Centre for the History of Medicine at University College London, my diagnosis is that the subject has now fully matured.

Conceptualized as a companion volume to The Western Medical Tradition: $800 \mathrm{BC}$ to $A D 1800$ by authors from the same centre, the new book provides in four large chapters a comprehensive synthesis of the development of medicine in the context of nineteenth- and twentieth-century Western society. Two general themes emerge: one is the increasing effect of the natural sciences in shaping medicine against the background of industrialization and modernization; the other is the gradual acceptance, by governments and the public alike, of
Western orthodox medicine as the arbiter in matters of individual and collective health. The history of 'alternative' medicine, although not ignored, does not receive particular treatment in this otherwise wide-ranging historical survey. There is, for example, no sustained discussion of the history of homeopathy.

Inevitably, perhaps, the broad overview in this book reflects certain trends and focal points in the historiography of medicine over the past 20 years or so. Accordingly, the history of public health and social welfare, of epidemics, of medicine in wartime, and the rise of modern hospital medicine take up a lot of space. Scientists central to the history of medicine, such as Rudolf Virchow, Louis Pasteur and Robert Koch, are treated in due detail. The book also raises awareness of historiographic methods. Stephen Jacyna, for example, in his chapter on the first half of the nineteenth century, discusses the approaches of Marxism and Michel Foucault to the history of medicine.

The book has a strong international perspective, covering developments in Germany and France, as well as Britain and the United States. It was not written strictly as a comparative history, but still provides valuable insight into different national styles of medicine. For instance, the strong drive towards medical specialization in Germany, the United States and France is contrasted with a resistance to this trend by British doctors that lasted until after the First World War. Medicine in Nazi Germany is treated in a separate section, but the presence of eugenic ideas and practices in
Western countries during the 1920 s and ' 30 s is emphasized in other parts of the book. Given this international approach, it is regrettable that the otherwise useful bibliographies for each chapter cite only English-language publications. This may be appropriate for a volume that is bound to become a key textbook for UK and US courses on the history of medicine, but the book's reach could have been made even wider by including, say, some French- and German-language scholarship in the field.

Another merit of this volume is that it contains one of the very few summaries of the history of Western medicine after 1945. The authors of this chapter, Anne Hardy and Tilli Tansey, focus on Anglo-American developments, but regularly contextualize them with data from various European countries. They also address the apparent paradox that despite undeniable progress in diagnostics, therapy medicine and biomedical research has become increasingly critical since the $1970 \mathrm{~s}$. The story of progress in medicine is also qualified by public criticism of the inequality in health-care provision between developing and developed countries, especially in the face of the HIV pandemic, the resurgence of tuberculosis and continuing problems with malaria control.

As this book shows, traditions in medicine and science can have a powerful influence on how health care is shaped for the future. I therefore recommend the book to anyone with a serious interest in understanding the interactions between the social and scientific events that have formed modern medicine. Andreas-Holger Maehle is head of the Department of Philosophy, Durham University, Durham DH13HN, UK.

In one ear: there's more to noise than unwanted sound, andit's not all bad. and disease prevention, public perception of

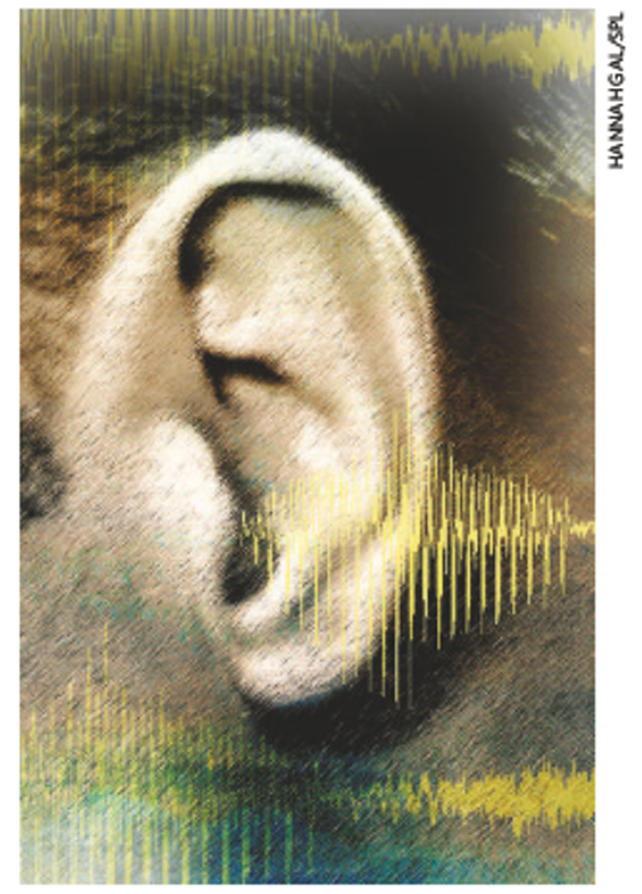

thesis that noise is "an unwanted signal" and develops ideas from information theory of noise in digital signals. The next two chapters cover noise in the everyday sense of unwanted acoustic disturbances. There is anecdotal material about unneighbourly behaviour, litigation, crematoria, noise from aircraft, the law on trespass, damage to hearing, noise-induced stress, and undersea noise involving the US Navy, dolphins and whales.

Much of the hard science, and its exposition in simple terms, is consigned to the (long) fourth chapter. Kosko covers a remarkably wide range of topics, from cosmology and photosynthesis to white and coloured noise, and the central-limit theorem. This is followed by a chapter including Fourier techniques and spread-spectrum encryption. The book ends with a discussion of stochastic resonance, an interesting phenomenon in which noise plays a creative role, rather than its usual destructive one. Here the addition of noise to a nonlinear tries to make it accessible and interesting to
the general reader. He opens with his central 